\title{
Pontifical
}

Academy of Theology

Cracow

\author{
Michael Heller
}

\section{ANTHROPIC IDEOLOGY THROUGHOUT THE AGES}

In the mind of every thinking person there is set aside a special room, a museum of wonders. Every time we enter that museum we find our attention gripped by marvel number one, this strange universe, in which we live and move and have our being.

J. A. Wheeler, from the Foreword to The Anthropic Cosmological Principle by J. D. Barrow and F. J. Tipler.

\section{INTRODUCTION}

At the Cracow Symposium of the International Astronomical Union in 1973 professor John Archibald Wheeler asked Brandon Carter ,to say something for the record about some ideas" that for some time had circulated among cosmologists ${ }^{1}$. In this way, the anthropic principle for the first time was shown to the public. Roughly speaking, it contains a set of ideas according to which ,it is not only that the man is adapted to the Universe", but also that „the Universe is adopted to man"2. To be more precise, the anthropic principle originates from the following observation:

The Basic features of the Universe, including such properties as its shape, size, age and laws of change, must be observed to be of a type that allows the evolution of observers, for if intelligent life

1 B. Carter, Large Number Coincidences and the Anthropic Principle in Cosmology, [in:] Confrontation of Cosmological Theories with Observational Data, ed. M. S. Longair, Reidel, Dordrecht 1974, pp. $291-298$.

2 J. A. Wheeler, Foreword to: J. D. Barrow, F. J. Tipler, The Anthropic Cosmological Principle, Clarendon Press, Oxford 1986, p. 1-2. 
did not evolve in a otherwise possible universe, it is obvious that no one would be asking the reason for the observed shape, size, age and so forth of the Universe ${ }^{1}$.

There is one, especially simple, aspect of the problem: after all, we do exist, and all possible world models that do not admit our existence are automatically falsified. At least in this way, some cosmological information is contained in the very fact that we are.

The anthropic principle (or better, the anthropic principles, since there circulate many non-equivalent its formulations) has earned enormous publicity among scientists, philosophers, and general audience. With no exaggeration one could say that the antropic ideology belongs to the most discussed issues ever inspired by the sciences. The goal of the present study is to try to understand this phenomenon. A working hypothesis is that man always looked for his place in the Universe and that the anthropic principles provide him new guide-lines in his struggle to find a meaning of his existence. To verify this hypothesis, or to make it more precise, would require a thorough study in the style of the "history of ideas”. The present paper should be regarded as a first reconnaissance along this way. I shall focus on the „extraterrestrial life debate” which has obvious ideological connections with tendencies giving force to the anthropic principles, and on philosophical implications of the Copernican revolution which spoiled man his cosmologically central position. Because of the richness of the available historical material, my discussion becomes more sketchy as it enters the after Galileo and Newton period of the modern sciences. All this makes of my conclusions only provisional suggestions pawing the way (let us hope) for better documented results.

Composition of the paper reflects the main epochs of the development of the Western philosophy and science.

\section{GREEK HERITAGE}

As almost everything in Western thought, man's attempts to determine his place in the Universe began with the Greeks (all earlier attempts dissolve in haziness and hypotheses). As place could be determined only with respect to its environment, no wonder that the question that had to be asked was: Are there other worlds? and only afterwards: Are we alone in all of them? In this way, the „extraterrestrial life debate" (to use a modem term) was preceded by the „plurality of worlds dispute” (time honoured expression). The atomists strongly supported the idea of the plurality of worlds, Aristotle objected it and claimed that the only one world could exist. The whole story is nicely told by Dick in the first chapter of his book devoted to the extraterrestrial life debate from

Democritus to Kant ${ }^{2}$. Here I want only to trace, the key points of the dispute, mainly

1 Ibid., p. $1-2$.

2 S. J. Dick, Plurality of Worlds - The Origins of the Extraterrestrial Life Debate from Democritus to 
to disclose its rationale and to establish initial directions of future developments.

1. First of all, from the very beginning the discussion was involved in the question of what should be meant by the term „Universe”. It is surprising that the understanding of this term by the early Greeks was very modern (in our standards).

The tradition was initially concerned not with the existence of Earthlike celestial bodies but with the plurality of kosmoi - cosmic systems composed of an Earth, planets and fixed stars ${ }^{1}$.

For Aristotle the world was ,the body enclosed by the outermost circumference" piece cut off from the infinite (apeiron)" which is ,a circumscribed portion of the sky, containing heavenly bodies and an earth and all the heavenly phenomena" 3 Only in the Renaissance (and especially in the post-Newton times) the interest will be shifted to planets and other celestial bodies as possible worlds by themselves. A curious thing is that it was the rigid Aristotelian doctrine of the sharp difference between the realm of Heaven and the physics of the sublunary region that prevented to consider single celestial bodies as separate worlds. The Earth at the natural centre of the world was a distinctive feature identifying the Universe.

The dispute of the plurality of worlds was often solved on purely linguistic grounds. It is clearly visible in the case of Parmenides for whom the Universe is unique by definition. Everything that exists constitutes the Being which for Parmenides was but the other name of the Universe.

2. The plurality of worlds dispute acquired its rationale from philosophical systems into which it was involved. It could not be otherwise since there were no other "scientific data" that would be able to provide any sort of reasonable evidence.

In the atomists view, worlds come into being by random motions of infinite number of atoms in the infinite void. Although the primary goal of this philosophy was to explain everyday phenomena, the doctrine of the plurality of worlds was, as it were, a necessary by-product of such explanations. Diogenes Laertius, the thirdcentury A. D. author, ascribes to Leucippus the following doctrine:

The worlds come into being as follows: many bodies of all sorts and shapes move by abscission from the infinite into a great void; they come together there and produce a single whirl, in which, colliding with one another and revolving in all manners of ways, they begin to separate like to like ${ }^{8}$.

In the Aristotle system, on the contrary, there was no logical necessity to consider „other worlds". If Aristotle considered them at length (in his On the Heavens) it was purely for the sake of discussion with the atomists. He strongly objected their doctrine of the plurality of worlds basing his arguments on the

Kant, Cambridge University Press 1984; as it can be seen from further footnotes, I owe much to this author.

1 Ibid., p. 2.

2 On the Heavens, book I, 278b (translated by W. K. C. Gurthie, Loeb Classical Library, Cambridge, Mass. 1960).

3 After Dick, Plurality of Worlds, p. 6. 
principles of his physics. If there are more than one worlds (in fact, two would be enough for the argument), each of them would have to have its own centre, and consequently any (simple) body moving naturally with respect to one of them would be moving non-naturally (violently) with respect to another.

Either, in fact - wrote Aristotle - we must deny that the simple bodies of the several worlds have the same natures, or if we admit it we must, as I have said, make the center and the circumference one for all; and this means that there cannot be more worlds than one?

3. The dispute gave origin to what later was called by Lovejoy ,the principle of plenitude" 10 . In discussions concerning the extraterrestrial life question it was many times employed either in its secular form as the fecundity of Nature argument or in its theological guise as the fecundity of God. One of the earliest formulations of this principle belongs to Lucretius, the Roman atomist, who wrote: „when abundant matter is ready, when space is to hand, and no thing and no cause hinders, things must assuredly be done and completed"1 2 .

4. Two other Greek philosophical principles were acting in the plurality of worlds dispute. First was the ,principle of perfection" which was to play so important role in shaping views of forthcoming generations on the structure of the Universe. It was used by Plato in arguing that Demiurg made a unique world to reflect the perfect unity of the Creator.

Have we, then, been right to call it one Heaven, or would it have been true rather to speak of many and indeed of an infinite number? One we must call it, if we are to hold that it was made according to its pattern ${ }^{12}$.

This could be thought of as a mere application to cosmological matters of the well known principle working in many fields of the Platonic doctrine (perfect ideas, perfect geometric figures, perfect motions of celestial bodies, etc.).

8 After Dick, Plurality of Worlds, p. 9.

9 On the Heavens, book 1, 276b.

10 A. O. Lovejoy, The Great Chain of Being, Cambridge Mass. 1971 (first edition in 1936).

2 De Rerum Natura, book 2, 1067-1069 (translated by W. H. D. Rowe, Loeb Classical Library, Cambridge, Mass. 1924).

12 Timaeus (translated by F. M. Comford, see, Theories of the Universe, ed. M. K. Munitz, The Free Press, New York, London 1957, p. 70). 
5. If to make the world perfect is considered to be the goal of Nature or of God, one is confronted with the ,principle of finality" (or the teleology principle). It will become one of the main philosophical components of the dispute till the present days. Plutarch in his De Facie in Orbe Lunae (which constitutes a part of his Moralia $^{13}$ ), directly considers the possibility of life on the other celestial body within our world, namely on the Moon. Strangely enough, Plutarch connects a theological argument with the view of impossibility of life on the Moon. According to Theon, a personage of the dialogue, the Moon cannot be Earthlike, since homing no life ,she would appear to have come into existence vainly and to no purpose" 14 . Plutarch's dialogue exercised a great influence on future thinkers.

6. Participants of the dialogue refer to arguments which seem to circulate among learned Greeks. Although the existence of life in other worlds was not very important for the Greek tradition, it was occasionally discussed. Both Epicurus and Lucretius expressed the view that other worlds host living creatures; the main argument was supplied by the principle of plenitude. As we have seen, the Moon attracted Greek's attention as a possible habitat of life. Plutarch was not an inventor of the idea; the tradition goes back to Thales and to the Pythagorean Philolaus. It is interesting to note that the first known description of a voyage to an Earthlike moon was given by Lucian of Samosata in his True History (about 200 A. D.). It is really difficult to find a new idea which would not be invented by the ancient authors!

\section{DISCARDED IMAGE ${ }^{15}$}

There are certainly more than one Medieval universes. Solely from a distance the Middle Ages look uniform and monolithic. Since in the present study (because of its review and compact character) I can deal only with a smoothed out picture, I shall distinguish only two Medieval universes: the one of average educated people, and the other of learned ones, philosophers and scientists of those days. Of course, there are strict interconnections between these two worlds. The former is certainly made out of pieces of the latter, but the pieces themselves are chosen in a highly selective way, and composed together by the work of imagination rather than by that of reasoning (something like the

13 Plutarch's Moralia: Concerning the Face which Appears in the Orb of the Moon, vol. XII, translated by H. Chemiss, Loeb Classical Library, London 1957.

14 After Dick, Plurality of Worlds, p. 21.

15 The title is borrowed from the book by C. S. Lewis (Cambridge University Press, Cambridge 1988, first edition in 1964). The present section is based on this book. Although the book's subtitle says that it is „An Introduction to Medieval and Renaissance Literature”, it helped me to understand some elements of the Medieval thought better than many other books on the history of science and philosophy. 
present popular world view which contains, to use C. S. Lewis' comparison, ,plenty of Freud and little of Einstein"16). The first is contained in the literature read by more or less educated people of the epoch, the second is a subject-matter of professional treatises written by specialists for fellow specialists in natural philosophy.

The importance of the medieval universe of educated people (the Model, as it is called by Lewis) for our culture comes from its enormous inertia. Great masters never take their world models so seriously as ordinary men. Usually they are well aware of many assumptions and disputed questions interfering into their mental constructs. Ordinary people stick to their imaginations once and for all. Therefore, in spite of the diversity of opinions in the Medieval natural philosophy, the common world view was stable and all-pervasive. And when it finally fell into pieces, the consequences of this disaster were felt throughout many centuries. They are felt even to-day.

C. S. Lewis ${ }^{17}$ enumerates three biggest achievements of the Middle Ages: Summa Theologiae of St. Thomas Aquinus, Dante's Divine Comedy, and the big synthesis of theology, history and science into a consistently overwhelming world model. In Lewis' opinion it had two major sources: books inherited from Antiquity and Medieval thinkers' own instinct of ,sorting everything out and tiding up”. There is no need to repeat here well known facts concerning rather casual selection of books that „iniuria temporum” allowed to pass the border of the Dark Centuries separating the Antiquity from the Middle Ages. The point is that the Medievals believed their books much more than they were entitled to, and they took literally almost everything that was written in them ${ }^{18}$. Since, however, the books were of various kinds and provenience, and contained many contradictory things, one had to introduce an order into them if one wanted to take them literally. It seems, therefore, that the Medieval instinct to put everything into order has a literary origin. Traces of it can be seen in the architecture of the Medieval world model: it is a work of art rather than a scientific construction. Let us notice that among conceptual tools of the Medieval world builders was the principle of perfection, but a concept of perfection itself changed quite substantially as compared with its Greek archetype: in the Middle Ages it seldom appeals to simplicity and often to hierarchical orders of beings. Another trace of the works of imagination rather than that of reason is the complete lack of any scale; for instance, the world is inhabited by both dwarfs and giants, but their actual size remains unkown. Gulliver „was a great novelty", and it opened a new epoch".

16 Ibid., p. 14.

17 Ibid., chapt. 1.

18 One can see the same tendency among present uneducated people; even our press has not taught them that the majority of ,what is written" could be a lie.

19 C. S. Lewis, Discarded Image, p. 102. 
It is a common belief that man had occupied a central position in the Medieval Universe and that it was the Copemican revolution that deprived him of this privileged place. Such a view is a typical half-true. The medieval world view was doubtlessly geocentric (and only in a sense, see below), but it never was anthropocentric. Alanus ab Insulis, in his De Planetu Naturae, expressed a then commonly shared opinion when he compared ,the sum of things" to a city. „In the central castle, in the Empyrean, the Emperor sits enthroned. In the lower heavens live the angelic knighthood. We, on Earth, are 'outside the city wall' ${ }^{20}$ '. Medieval people assimilated the view of Macrobius (very influential author from the end of the 4th century) that the highest heaven are made out of the most limpid (liquidissimum) stuff, the starry sky out of all what is still enough gross (corpulentum), and all ,that was irreclaimable” (vastum), ,sank down and settled at the lowest point" to form the Earth which is but an ,offscourings of creation, the cosmic dust-bin" 21 .

How this view could agree with the geocentric cosmology?

Because, as Dante was to say more clearly than anyone else, the spatial order is the opposite to the spiritual, and the material cosmos mirrors, hence reverses, the reality, so that what is truly the rim seems to us the hub ${ }^{22}$.

It was certainly not geometry that provided symmetries to construct the Medieval Universe. „The Medieval Model is, if we may use the word, anthropoperipheral. We are creatures of the Margin" ${ }^{23}$.

\section{THE COPERNICAN REVOLUTION}

The final result would have amazed even Copernicus.

S. Toulmin, J. Goodfield, The Fabric of Heaven, p. 180

The Medieval astronomy left to its successors two traditions: a collection of algorithms to compute positions of heavenly bodies, and a general image of the world. The former ,had remained effectively unchanged from Ptolemy's time” the latter „was an amalgam of Aristotle's physics and Ptolemy's epicycles, embedded in a setting constructed by Neoplatonic mystics and Christian theologians ${ }^{24}$. Against a widespread believe that the main objective of Copernicus was to destroy the second (so to speak, cosmological) tradition, it is historically absolutely certain that his work

Ibid., p. 58.

Ibid., pp. $62-63$.

Ibid., p. 58.

22 Ibid., p. 58.

${ }^{24}$ S. Toulmin, J. Goodfield, The Fabric of Heaven, Harper and Row, New York, 1961, p. 161. 
should be situated entirely within the first (so to speak, professional) stream of research. Although one cannot deny that the Copernican achievement was pregnant not only with philosophical and theological consequences, but also with the most general factors which influence man's attitude towards reality including himself. However, they were to be disclosed later on, quite independently of Copernicus' own intentions. These factors will constitute a subject-matter of my analysis in the present chapter.

Karl Popper once distinguished between scientific revolutions and ideological revolution ${ }^{25}$. Roughly speaking, by ,ideology” Popper understands ,any nonscientific theory or creed or view of the world which proves attractive, and which interests people, including scientists". Scientific revolution is "a rational overthrow of an established scientific theory by a new one", and ideological revolution comprises ,all processes of 'social entrenchment' or perhaps 'social acceptance' of ideologies, including even those ideologies which incorporate some scientific results". The Copernican and Darwinian revolutions are for Popper typical examples. „They clearly were scientific in so far as each of them overthrew a dominant scientific theory", and they were also ideological ,in so far as they both changed man's view of his place in the Universe" ${ }^{26}$. In the following I shall focus on ideological aspects of the Copernican revolution.

It is a commonplace to claim that the essence of the Copernican (ideological) revolution consisted in depriving the humankind of its (geometrically) privileged central position in the Universe. I dare say that it is both a simplification and an underestimate of what really happened in the 16th century. Of course, I do not deny that the realization that the Earth had been degraded to the role of an average planet had an enormous impact on human imagination, but this came later and as a result of other transformations in human mentality. As we have seen in the preceding chapter, people of the Middle Ages did not attach such a significance as we do to the central position of the humankind in the Universe. The vision of the world was not anthropocentric but theocentric, and it is my guess that people, educated in the Medieval tradition, would be ready to give up their central position, provided the role of God was safeguarded. And exactly this seemed to be in danger.

In my opinion, the work of Copernicus triggered the following processes:

(1) abolishing the strict border between the „earthly physics” and the ,physics of heavens",

(2) dehierarchization of the Universe,

(3) its geometrization, and

(4) its infinitization, and strangely enough,

25 K. R. Popper, The Rationality of Scientific Revolutions, [in:] Problems of Scientific Revolution (The Herbert Spencer Lectures 1973), ed. R. Harre, Clarendon Press, Oxford 1975, pp. 72 - 101.

26 Ibid., p. 88. 
(5) narrowing the concept of „other worlds" which no longer referred to literally different universes, but rather to different ,planets”, or „,moons”, or „stars” within the same (infinite) Universe.

The strict dichotomy of the ,earthly physics” and the ,physics of heavens”, together with the ideas concerning a hierarchical structure of the world were, in the Middle Ages, not only pillars of the Aristotelian science, but they also coalesced with theological ways of thinking about God's relation to the world. Although theologians always knew that God transcends possibilities of our imagination, they were unable to imagine limits of their own imagination, and fitted the idea of God into the idea of their Universe. When their cosmology begun to collapse, they felt their theology were endangered ${ }^{27}$.

As we have mentioned earlier (see, chapter 2), the Medieval Universe had no definite scale with the help of which its size could be determined, but - to use analogy with a modem topological concept - it was compact with God's abode providing a kind of its boundary. (Let us stress out the analogical, or even metaphorical, character of this comparison. The Medieval Universe was architectural or hierarchical rather than geometrical, and to apply to it any geometric (or topological) terms, strictly speaking, is meaningless.) The process of „decompactification” of the Universe started before the Copernicus times (to mention only Nicholas of Cusa and Nicole Oresme), but there cannot be any doubts that the Copernican Revolution gave a tremendous momentum to this process. Alexander Koyre insists that the essence of the transition from the Medieval cosmology to the modern world picture was provided by "destruction of the Cosmos" and ,geometrization of space". The former consisted „In substituting for the finite and hierarchically ordered world of Aristotle and Middle Ages [the Cosmos], an infinite Universe, connected by the identity of its components and the uniformity of its laws"; whereas the latter consisted in „substituting for the concept of the Aristotelian concrete space (as a collection of 'places') the abstract space of the Euclidean geometry, considered as real" 28 . The process was long, it matured in ideas of Descartes and was given a modern form in Newton's Principia, but even this last step could be thought of as a consequence of the Copernican setting the Earth into motion ${ }^{29}$.

Copernicus himself did not discuss these things. In his De Revolutionibus..., he only hinted that all celestial bodies have a ,natural inclination” to gravitate to each other $^{30}$, and avoided discussing ,the question whether the Universe is

27 See, N. M. Wildiers, Weltbild und Theologie, Benziger Verlag, Zurich, Einsiedeln, Koln 1974.

28 A. Koyre, fctudes d'histoire de la pensee philosophique, Gallimard, Paris 1971, p. 258.

29 See, A. Koyre, Du monde clos a I'univers infini, Presses Universitaires de France, Paris 1962.

${ }^{30} \quad{ }^{0}$ De Revolutionibus..., liber I, caput 9; English translation by J. F. Dobson and S. Brodetsky [in:] Theories of the Universe, ed. M. K. Munitz, The Free Press, New York, London 1957, pp. 149173. 
finite or no" by leaving it to philosophers of nature ${ }^{31}$. However, there were others who developed potentialities latent in the Copernicus work.

In this context one cannot forget Giordano Bruno and his proliferous writing on the infinity of the Universe and plurality of worlds. There is no doubt that Bruno was a dedicated Copernican; however, his astronomical views were entangled in a net of a hermetic philosophy viewing Nature in animistic and magical categories. In Bruno's cosmology philosophical speculations and imagination were more powerful tools than sound astronomical reasoning. Bruno explicitly denied the Aristotelian argument that there must be only one world since otherwise the existence of more than one centres would destroy the natural character of motions of heavy bodies (see, chapt. 1). Since the Universe is infinite it has neither the centre nor circumference. Every celestial body is the world of its own, and elements of this world tend to its own centre ${ }^{32}$.

Johannes Kepler is of outermost importance in our story. His discovery of the elliptic planetary orbits finally demolished the old myth of the perfect circular motions of heavenly bodies and paved the way to the complete unification of the celestial and earthly physics. This is very well known, and I will not repeat it here. I prefer to focus on a less known aspect of the rich Keplerian heritage.

Personally, Kepler stood at the threshold of two epochs. He leaned ahead with his astronomical discoveries, his experimental abilities, and his mathematical skill to analyse phenomena, but he was also dedicated to the Neoplatonic tradition with its obsession with perfect symmetries, to Pythagorean magic of numbers, and astrology ${ }^{33}$. Since his early steps in astronomy, Kepler was fascinated by Plutarch's work De Facie in Orbe Lunae (see, chapt. 1), and tried to figure out how the motions of celestial bodies would appear from the surface of the moon. In various periods of his life, Kepler came back to this idea. Finally, not long before his death, he completed the work which appeared posthumously. The work bears the title Somnium seu Astronomia Lunaris (Dream or Astronomy of the Moon). Friendly spirits take the hero of the story to the Moon, called by Kepler Levania. The Moon's geography, inhabitants and their cities are picturesquely described, but the main attention of the author is focused on the view of the lunar sky.

...Here he attends to all phenomena which are presented by the sun, the earth, the planets as regards their motion, their light and their sizes for the dwellers of the moon, both on the side turned toward us and that turned away ${ }^{34}$.

31 Liber I, caput 8. The English translation says: „Let us then leave to Physicists the question...” (p. 162), but adds the footnote noticing that by Physicists commentators of Aristotle's Physics should be meant.

32 More about Bruno's views related to our main topic see, Dick, Plurality of Worlds, pp. 63 - 69.

33 See, G. Holton, L'imagination scientifique, Gallimard, Paris 1981, chapt. II: L'univers de Johannes Kepler: physique et metaphysique, pp. 48-73.

34 M. Caspar, Kepler 1571-1630, Collier Books, New York 1959, p. 364. 
In Kepler, a story-teller competed with an astronomer. The author equipped his Dream with ample notes containing many astronomical details. In one of such notes Kepler revealed his intention: „The purpose of my Dream — he wrote — is to use the example of the moon to build up an argument in favour of the motion of the earth $^{35}$ ". I think the argument is important, also from the psychological point of view: for the first time, an observer was moved out of the Earth and looked at the Universe from other celestial body. In modern cosmology the so-called Copemican Principle (or the Cosmological Principle) is known which, roughly speaking, asserts that the average picture of the Universe is the same irrespectively of the place from which it is viewed. Perhaps the first indication that something like the Copernican Principle was to be formulated appeared in the title of the book, published in 1640, by an Anglican clergyman John Wilkins: Discourse concerning a New Planet, Tending to prove, that 'tis probable our earth is one of the Planets. In it Wilkins wrote: „If our earth were one of the Planets..., then why may not another of the Planets be an earth" 36 . We can see that the Earth begins to be shifted from its central place to that of an average planet in the world. However it goes without saying that the road from the Copernicus' original work to the principle honoured with his name was long and laborious. Kepler's Dream hinted the direction.

It was only after the process of geometrization of space has been completed (and this had happened not before Descartes and Newton, see below), when people started to regard the Copernican revolution in terms of the loss by the humankind its geometrically central position in the Universe. This had enormous impact on modern mentality, but the drama begun in a non-geometric qualitative world of the Aristotelian physics and common imagination.

\section{THE ANTHROPOMETRIC UNIVERSE}

Geometrization and infinitization of space was an outcome (or perhaps a byproduct, albeit an important one) of another process taking place in developments of scientific thought from the Antiquity and Middle Ages till the beginning of Modern Times, namely of the mathematization of science. The process was already clearly visible with Archimedes, it always was well nested in astronomy, and at the end of the Middle Ages slowly intensified in the science of motion and light. It was paralleled, and sometimes dominated, by mystical approach to numbers and mathematics in general. This approach begun with the Pythagoreans, was not foreign to Plato, and formed quite pronounced stream of thought in the Middle Ages. As we have seen, these two traditions met in Kepler's personality and work. On the one hand, his achievements in celestial 
mechanics and optics made out of him an outstanding representative of the new spirit of mathematical science closely connected with observation and experiment; on the other hand,

...the symbolism of numbers and of solids still had him in their sway. He felt that to understand the structure of the universe, he had to immerse himself in a sort of cryptography. His inquiry fused physics and theology into one ${ }^{37}$.

Analytical geometry, created by Descartes ${ }^{38}$, was an essentially new step in developments of mathematics. It not only gave a new powerful tool in geometric investigations of nature, but also strongly influenced Descartes' own philosophical thinking. It is evident that his criterion, stating that what is ,clear and distinct" necessarily must be true, and his method of acquiring true knowledge, was suggested to him by his work in geometry, and was tested by him in the field of geometric investigations (it is worth noticing that Decartes Discourse of Method and his Geometry, together with Dioptrics and Meteorology, were originally published under the same cover ${ }^{39}$ ).

In 1644 Descartes published his Principles of Philosophy in which he proposed the first, after Aristotle, complete system of physics. Although it was soon to be replaced by the great Newtonian synthesis, it continued to exercise a great influence on a few generations of thinkers, especially in France. My guess is that the force of the Cartesian system of the world consisted in its appeal to imagination: physics of direct contact (vortices, collisions, fractions,...) seemed to explain everything, and the lack of mathematical models was replaced by insisting on the „clear and distinct" character of proposed mechanisms. One of greater problems the contemporaries had with the Newtonian physics was how to enforce imagination to surrender to mathematical models (to mention only discussions concerning the nature of gravitational force, action on distance, etc.). With the Cartesian system there were no such difficulties; the deceptive methodology of Descartes created the universe smoothly adapted to possibilities of the human imagination.

The Cartesian world extended to infinity (Descartes himself preferred to call the Universe indefinite rather than infinite, reserving infinity to God), and its extension was identified with matter filling it in. In such a world mechanical explanations completely eliminated any mentioning of final causes. In Descartes' opinion, „man cannot presume to know for what ends all things were created,

37 E. Cassirer, Mathematical Mysticism and Mathematical Science, [in:] Galileo - Man of Science, ed.: E. McMullin, Basic Books, New York, London 1967, pp. 339_351; quotation from p. 347.

38 The Geometry of Rene Descartes with a Facsimile of the First Edition, translated by D. E. Smith and M. L. Latham, Dover Publ., New York (the year of publication is not indicated).

39 The full title of the book run: Discours de la Methode pour bien conduire sa raison et chercher la verite dans les sciences, plus la Dioptrique, les Mitiores et la Geometrie, qui sont les Essais de cettes methodes. 
66 except that in all probability they were not created for man himself ${ }^{40}$. In this way, Descartes eliminated „human affairs” from his physics. Strict Cartesian dichotomy: „extended matter” for physics, and „conscious substance” for philosophy, not only have created new trend in modem philosophy, but also have sanctioned the complete removal of any aspects of human consciousness from physics. Thinking about physics does not require taking account that physics is thought about.

Equivalence of extension and matter amounted to the equivalence of geometry and physics. The Cartesian world was especially fitted to push farther another aspect of the Copernican Revolution: in the indefinite Universe there is no centre, and infinitely many vortices effectively liquidate the privileged position of our vortex, i.e. of our planetary system. Descartes himself avoided to elaborate this topic, but his followers did not hesitate to do this for him. Fontenelle certainly was the most read author of his time. His Entretiens sur la pluralite des mondes (1686) fully deserve the name of a bestseller. Till the end of the eighteenth century it had sixteen editions in Paris alone, and five different English translations. „If the fix'd stars - wrote Fontenelle — are so many Suns, and our Sun the centre of a Vortex that turns round him, why may not every fix'd Star be the centre of a Vortex that turns round the fix'd Star?"41 This was understood, both by the author himself and by his readers, as a retoric question. And if the number of vortices is infinite, why in some of them beings similar to ourselves could not be found?

Perhaps the more scientific, but only a little less widely read, was Cosmotheoros written by Huygens, published posthumously in 1698. His statement that „our Star has no better attendance than the others" 42 could be thought of as one of the first formulations of the cosmological (or Copernican) principle.

It is not an exaggeration to say that the topic ,plurality of worlds" not only fascinated people of the eighteen century, but also became a subject-matter of a broad discussion covering all possible levels of sophistication: from theological speculations to subtle interpretations of telescopic data (mainly concerning the Moon, Jupiter, and Saturn).

However, the most important thing regarding the ,place of man in the Universe" did not happen in the heated discussions on the plurality of worlds and humanlike beings inhabitating them, but in the methodology of science. Strangely enough, as an infinite universe was more and more populated with Suns and planets, and their dwellers, man as a thinking subject was more an more radically removed from the scientific method. The process of the formation of this method was much more tedious and complicated than

40 After Dick, Plurality of Worlds, p. 107.

41 After Dick, Plurality of Worlds, p. 126.

42 After Dick, Plurality of Worlds, p. 133. 
nowadays commonly thought. It culminated in the works of Galileo and Newton who became symbolic personnages of the new science. Unfortunately, being unable to trace here this extremely important process, I will focus on some of its outcomes especially significant as far as the elucidation is concerned of the relationship between men and the Universe. The point is that from now on it is not an imagination (even if it is sometimes fed with astronomical data) but the practice of doing science that will most effectively shape man's interactions with the world.

Alexandre Koyre, in his famous study on different aspects of the Newtonian achievement $^{43}$, expresses the view that Newton's Principia were an implicit polemic with the Principles of Descartes (which is signalled in the title itself). The fact is that the Newtonian mechanics effectively replaced Cartesian physics, although the process was by no means easy and automatic. However, by the mideighteenth century, even in France, the Cartesian system irrevocably begun to give place to the Newtonian world view. On the cosmological stage, the indefinite Cartesian plenum was replaced by mostly empty, infinite, and absolute space populated with infinitely many stars, some of them possibly having planets hosting life and intelligence. On the physical stage, the rearrangement was by far more drastic. As noticed by Rene Thom, „Descartes explained everything but calculated nothing", Newton, on the other hand, „explained nothing, but calculated everything" 44 . Newton himself insisted that „mathematical forces” are not „true causes" but only a kind of working scientific fiction. Many generations of thinkers believed that calculations can only deal with phenomena not giving any deeper insight into the nature of things. Only now we begin to understand that „calculations" constitute an entirely new way of explaining the world.

The impact of the „Newtonian method" on the manner of seeing the world was not immediate but far-reaching and radical. Its most conspicuous features are:

(1) Mathematization of science which in a common redeption (including scientists and philosophers) amounted to the transition from the purely qualitative world of sensual perceptions to the quantitative world ,given" us through numerical outputs of experiments.

(2) Mechanization of cosmology. However, it was only in a vulgar view that the Universe was regarded as a mechanical device (a clock, for instance; this comparison was made already by Fontenelle), and it belonged rather to a Cartesian heritage than to the Newtonian interpretation. In fact, Newtonian gravity, with its action on distance, introduced into the world a highly abstract element, and if the world of classical science could be termed mechanical, it was only because the very concept of the cosmic machine evolved together with the

43 Etudes newtoniennes, Gallimard, Paris 1968, especially pp. 85-154.

44 Stability structurelle et morphogenese, Inter-Editions, Paris 1977. 
increase of sophistication of the mechanics itself. Perhaps the main property of the cosmic design justifying the name „mechanism” was

(3) its strict determinism. Of course, one should remember that it took quite a time for the Newtonian view of the world needing Good's corrections ${ }^{45}$ to change into the Laplacian unverse in which everything, up to the minutest detail, is prearranged in the initial conditions ${ }^{46}$.

(4) Another feature of the new science, perhaps less easily visible but abundantly pregnant with consequences, was elimination of the „cognizing subject" from the scientific method. As it was clearly expressed by Schrodinger:

...it amounts to a certain simplification which we adopt in order to master the infinitely intricate problem of nature. Without being systematic about it, we exlude the subject of cognizance from the domain of nature we endeavour to understand (Schrodinger calls this statement the objectivation principle $)^{41}$.

People of the post-Newtonian era were not fully aware of the fact that this elimination was a methodological procedure; they felt immensely alienated from the world science had developed before their eyes.

If the Universe were ever anthropocentric, now it has definitely lost its centre focused on man. Man's subjectivity has been banished from science and effectively replaced by man's measurement activities with the help of which human science constructs its theories and models. To use Harrison's expression, the Universe has become anthropometric ${ }^{48}$.

Whitehead, in the fifth chapter of his Science and the Modem World ${ }^{49}$ beautifully describes a romantic reaction to the mechanization of the Universe and the fear it aroused in people constrained to live in such a world. One line of Tennyson renders them both: impersonal power of the mechanistic sky, and the fragile nature of human feelings:

„The stars”, she whispers, ,blindly run”.

\section{COSMIC LONELINESS}

The „methodological absence” of human subjectivity in the physical sciences, from around mid-eighteen century on, is an accomplished fact. A more

45 See, D. Kubrin, Newton and the Cyclical Cosmos: Providence and the Mechanical Philosophy, [in:] Science and Religious Belief, ed. C. A. Russel, University of London — The Open University Press, London 1973, pp. 147-169.

46 See, R. Hahn, Laplace and the Mechanistic Universe, [in:] God and Nature, ed. D. C. Lindberg, R. L. Numbers, University of California Press, Berkeley 1986, pp. 256-276.

47 E. Schrodinger, Matter and Mind (under the same cover with ,What is Life?"), Cambridge University Press 1969, p. 127.

48 E. Harrison, The Science of the Universe, Cambridge University Press 1953.

49

Cambridge University Press 1953. 
detailed historical study of this phenomenon would be needed to reveal its many faces and its powerful impact on philosophy and general culture. To do this goes beyond the scope of the present paper. Everything I can do here is to draw a few lines to sketch the situation.

Materialistic and positivistic interpretations of science (both promoted by the French Enlightenment and widely spread in the nineteenth century) made this „absence of man” more, so to speak, clearly transparent. Materialistic interpretation of science reduced human subjectivity to inert properties of matter, and the positivistic way of thinking forebode to look for subjectivity outside the field controlled by the empirical method. To be sure, there were many attempts to do exactly the opposite, but they were negated the name of science. As we have noticed above, it was within the Cartesian system where the definite split took place between dehumanized science and subjectivistic philosophy. In the history of thought, Descartes is considered to be the father of the modern „,conscious subject philosophy". The stream of this philosophy flows through German idealistic schools to the present forms of phenomenology and existentialism. Relationships between these systems and science are notoriously bad, if any.

There is a historical evidence that the „conscious subject philosophy” is a byproduct of the Copernican revolution. A. Koyre in his profound studies on the German mysticism of the fifteenth century came to conclusion that the German mystics, such as Franck, Weigel, and first of all Boehme, cannot be understood without taking into account the post-Copernican scenery ${ }^{50}$. Mystic experience of Boehme should be regarded as a reaction on a "cosmic loneliness" caused by denying the humanity the central role it had played in the by-gone system of the world $^{51}$. „If it is true - writes Koyre - that Hegel genuit Marx, it must be acknowledged that Boehme genuit Hegel ${ }^{52}$." In Koyre's opinion, German idealistic philosophy is a continuation and a de- christianized version of the earlier German mystical theology. Direct dependencies can be found both on the level of doctrine and of verbal enunciations as well. For instance, Koyre argues that „In Ja und Nicht bestehen alle Dinge" of Boehme became the dialectical principle of the unity of contradictions in the Hegelian system.

A tension between ,philosophy of conscious subject” and science culminated in Husserl's Crisis of the Western Sciences. In this little book, considered by many as the best twentieth century philosophical assessment of science, Husserl forcibly argues that one can truly speak of a treason of the man's case by the sciences. In spite of the fact that they assure a kind of prosperity to the humankind, the modern sciences have postponed asking questions which ,for

50 After Jorland: La science dans la philosophie, Gallimard, Paris 1981.

51 See also, G. Jorland, pp. 174 f, 204.

52 After Jorland, p. 196, footnote.

70 the authentic humanity are decisive questions". This fully justifies — in Husserl's view - speaking of the deep crisis in the „European science" 53 .

Another big issue concerning the ,problem of man" in the modern period is the appearance of the Darwin work and further developments of the theory of 
evolution. Apart of the first shock and many misunderstandings, caused mainly by fanaticism (of both sides) and ignorance (of one side), its lasting effect in the „cultural consciousness" was the feeling of a new degradation of man who, as a biological species, had been incorporated into the course of nature and pulled down from his role of the king of creation to a level of a higher animal. For many this was a final ,descent of man”, his ultimate reduction, through the world of animals and plants, to the inanimate nature ${ }^{54}$.

The extraterrestrial life debate did not stop after Newton and Fontenelle, on the contrary, the number of books and essays dealing with the problem increased enormously ${ }^{55}$ (as documented by Crowe, by 1916 the debate has produced more than 140 books on the topic ${ }^{56}$ ). The most outstanding astronomers, such as Lalande, Herschel, Flammarion, Newcomb, Lowell, took part in the debate which always aroused interest of the public and, lacking any serious empirical evidence, remained inconclusive. Man's fascination with the Universe and Man's looking for his place in it continued to exercise their influence as driving forces of the dispute, but no radically new philosophical ideas (such as once was provided by the Copernican revolution) were involved into the problem. And one must say, the extraterrestrial life debate more and more often was treated as a science fiction rather than truly scientific problem. Hubble in his famous Realm of the Nebulae wrote: „Not until the empirical results are exhausted need we pass on to dreamy realms of speculation $^{57}$ ". In the extraterrestrial life debate the empirical results are not only not exhausted, but they did scarcely begin to speak.

The feeling of a ,cosmic solitude" was well established in many major streams of thought in the beginning of our century. No wonder people got excited when the role of an observer was stressed by the theory of relativity and

53 E. Husserl, Die Krisis der europaischen Wissenschaften und die transzendentale Phanomeno- iogie, W. Beimel, Haag 1954.

54 From a deluge of books and papers on philosophical and theological implications of the theory of evolution I will quote, as an unfair sample, only the following: Science and Religious Belief, ed. C. A. Russell, University of London Press - The Open University Press, London 1973; Evolution and Creation, ed, E. McMullin, University of Notre Dame Press, Notre Dame 1985; God and Nature, ed. D. C. Lindberg, R. L. Numbers, University of California Press, Berkeley 1986; Evolution and Creation, ed. S. Andersen, A. Peacocke, Aarhus University Press, Aarhus 1987.

55 Dick's monograph on the plurality of worlds ends with Kant; the period from Kant to the beginning of our century is covered by M. J. Crowe, The Extraterrestrial Life Debate, Cambridge University Press, 1986.

56 Ibid., Appendix.

57 Dover Publ., New York 1958, p. 202. 
when quantum mechanics seemed to include an observer into its both formal and conceptual scheme. John von Neumann, to whom quantum mechanics owes its axiomatic formulation ${ }^{58}$, thought that there was no sharp dividing line between quantum processes and the measuring device which is part of a conscious observer. Similarly, Eugene Wigner emphasised that the interaction of human consciousness with the physical system should be held responsible for the wave function collapse in the act of quantum measurement ${ }^{59}$. It is often argued that we never know any quantum process as it is in itself but only as it interacts with the observation process. A huge discussion lasts to the present days concerning the role of a conscious observer in quantum mechanics; the scatter of opinions is enormous: from those who believe that quantum mechanics has finally restored the position of man in science by showing that the assumption of the world existence is meaningful only if the Universe is regarded as being cognized by a human subject to those who assert that the observer in quantum mechanics could be equally well replaced by a system of photo-cells and computers ${ }^{60}$. Recent ramifications of this discussion have direct connection with the anthropic principles ${ }^{61}$.

However, these are more or less philosophically inspired speculations; in the scientific practice, the principle of objectivation formulated by Schrodinger (see above, chapt. 4) works, and the feeling of man's alienation from science persists. I will end this chapter with quoting two influential authors witnessing to this feeling.

The first is Jacques Monod who in his Le hasard et necessite makes of this feeling his central philosophical thesis. The corner stone of the scientific method is the ,principle of objectivity" that is to say ,a systematic refusal [...] of any interpretation of given phenomena in terms of final causes"62. There is nobody in the Universe, except for man, who could impose a ,rational project" onto what exists. „The Universe remains deaf to his music, indifferent with regard to his hopes, to his sufferings and to his crimes ${ }^{63}$ ".

The second quotation is taken from another bestseller of our times, Steven Weinberg's The First Three Minutes. On the very last page we read:

As I write this I happen to be in an airplane at 30,000 feet, flying over Wyoming en route home from San Francisco to Boston. Below, the earth looks like very soft and comfortable-fluffy clouds

58 J. von Neumann, Mathematical Foundations of Quantum Mechanics, Princeton University Press, 1955.

59 E. P. Winger, Remarks on the Mind-Body Problem, [in:] The Scientist Speculates, ed. I. J. Good, Heinemann, London 1961.

${ }^{60}$ See, for instance, J. A. Wheeler, W. H. Zurek, Quantum Theory of Measurement, Princeton University Press, 1983; B. d'Espagnat, Une incertaine rialitb, Bordas, Paris 1985.

${ }_{61}$ See, J. D. Barrow, F. J. Tipler, The Anthropic Cosmological Principle, Clarendon Press, Oxford 1986, chapter 6.

62 J. Monod, Le Hasard et necessity, Ed. de Seuil, Paris 1970, p. 37.

«Ibid., p. 216. 
here and there, snow turning pink as the sun sets, roads stretching across the country from one town to another. It is very hard to realize that this all is just a tiny part of overwhelming hostile universe. It is even harder to realize that this present universe has evolved from an unspeakably unfamiliar early condition, and faces a future extinction of endless cold or intolerable heat. The more the universe seems comprehensible, the more it also seems pointless ${ }^{64}$.

There is only a solace, ,in the fruits of our research”:

The effort to understand the universe is one of the very few things that lifts human life a little above the level of farce, and gives it some of the grace of tragedy ${ }^{65}$.

\section{MODERN ANTHROPIC PRINCIPLES}

So far everything was intended to set a context for the anthropic principles. They appeared on the scene quite suddenly in the sixties and seventies of our century, but ex post it can be seen that their appearance was foreboded much earlier. Eddington's speculations concerning the role of large dimensionless numbers in the interconnection between microphysics and the large scale structure of the Universe $^{66}$, and Dirac's hypothesis to explain some of these large number coincidences ${ }^{67}$, could be thought of as paving the way for the explicit formulations of the anthropic principles. The history of these principles begins in 1961 when Dicke noticed that the period of time in which the Universe could be investigated by a physicist is strictly limited by the fact ,that the carbon is required to make a physicist". Therefore,

...the minimum time for the start of the epoch of man is set by the age of the shortest-lived stars, for elements other than hydrogen, are formed in the interior, and distributed at the death of the star. [And] ....an upper limit for the epoch of man is set by requirement that he has a hospitable home in the form of a planet circling a luminous star. This time is set by the maximum age of a star capable of producing energy by nuclear reactions ${ }^{68}$.

It was Brandon Carter who gave the name ,anthropic principle” to this idea. In his talk at the IAU Cracow Symposium ${ }^{69}$, he distinguished the weak anthropic principle, asserting that ,we must be prepared to take account of the fact that our location in the Universe is necessarily privileged to the extent of

64 A. Deutch, London 1978, p. 154.

65 Ibid., p. 155.

66 A. S. Eddington, The Mathematical Theory of Relativity, Cambridge University Press 1923; Fundamental Theory, Cambridge University Press 1946.

67 P. A. M. Dirac, The Cosmological Constants, Nature, 139, 1937, p. 323; New Basis for Cosmology, Proc. Roy. Soc. London, A 165, 1938, pp. 199-208.

68 R. H. Dicke, Dirac's Cosmology and Mach's Principle, Nature, 192, 1961, p. $440-441$.

69 B. Carter, Large Number Coincidences and the Anthropic Principle in Cosmology, [in:] Confrontation of Cosmological Theories with Observational Data (IAU Symposium), ed. M. Longair, Reidel, Dordrecht 1974, pp. $291-289$. 
being compatible with our existence as observers"70, and the strong anthropic principle, postulating that ,the Universe (and hence the fundamental parameters on which it depends) must be such as to admit the creation of observers within it at some stage ${ }^{71}$ ".

The style of thinking in terms of the anthropic principles (the Universe is such as it is because it is being observed by us) was surprisingly quickly accepted and spread among cosmologists. Anthropic ideology was used to explain some purely scientific questions ${ }^{72}$, and people begun to hunt for new ,anthropic coincidences"73.

Even in its most modest formulations the anthropic doctrine bears some philosophical connotations; no wonder, therefore, that it quickly crossed the borders of science and entered regions of metaphysics. It is no surprise that it revived old discussions concerning the argument of design ${ }^{74}$, but it also assumed the form of a Berkeley-like philosophy stating that the „observers are necessary to bring the Universe into being" (the so-called participatory anthropic principle) ${ }^{15}$, and led to radically optimistic formulations, known as the final anthropic principle, postulating that ,intelligent information processing must come into existence in the Universe, and, once it comes into existence, it will never die out ${ }^{76}$ ".

The last formulation became a focal point of the extensive monograph by J. D. Barrow and F. J. Tipler bearing the title The Anthropic Cosmological Principle ${ }^{11}$. The authors provide a broad historical perspective for the anthropic ideology, trace all vestiges of the anthropic style of thinking in the sciences, do not hesitate to follow its boldest philosophical ramifications. Their arguments culminate in a model of the „Omega Point”, an Ultimate Observer, residing at a suitable point of the future causal boundary of space-time that gives a meaning to the entire previous history and ensures a kind of perpetuity to the „,intelligent information processing”. The Omega

70 Ibid., p. 293.

7 Ibid., p. 294.

72 See, for example, C. B. Collins, S. W. Hawking, Why is the Universe Isotropic?, Astrophys. J., 180, 1973, pp. 317-334.

73 Perhaps the best known paper of this series is: B. J. Carr, M. J. Rees, The Antrophic Principle and the Structure of the Physical World, Nature, 278, 1979, pp. 605-612.

74 See, for example, J. Leslie, God and Scientific Verifiability, Philosophy, 53,1978, pp. 71-79; Anthropic Principle, World Ensemble, Design, American Philosophical Quarterly, 19, 1982, pp. 141151.

75 J. A. Wheeler, [in:] Foundational Problems in the Special Sciences, ed. R. E. Butts, J. H in tikka, Reidel, Dordrecht 1977, p. 3; The Nature of Scientific Discovery, ed. O. Gingerich, Smithsonian Press, Washington 1975, pp. 261—296, 573—587.

76 L. D. Barrow, Anthropic Definitions, Quarterly Journal of the Royal Astronomical Society, 24, 1983, pp. 146-153.

77 Clarendon Press, Oxford 1986.

Point idea was later developed by Tipler in the form of ,a model of an evolving God"78.

The book by Barrow and Tipler has made the anthropic principle debate still more heated and more popular. It is no exaggeration in saying that the anthropic 
principle issue belongs to the most discussed topics having their origin in modern science. The discussion begun among cosmologists, it was soon taken over by philosophers, and now it is a kind of a public property: popular books and mass media are full of anthropic ideology for an average reader, mixed with all sorts of a philosophical comment - from traditionally minded design arguments to new anthropocentric visions of the world.

It is not my goal to asses (or to enter into discussion with) different formulations of the anthropic principle and their various philosophical interpretations, but only to try to understand - on the light of the history of man's attempts to determine his position in the Universe - the significance of contemporary anthropic principles in this process. After this lengthy study I am ready to formulate my tentative conclusions.

\section{TENTATIVE CONCLUSIONS}

First of all, I should once more remind the reader that my intention is not to assess scientific merits of the anthropic principles, but only to show a historical background of the anthropic doctrine and its interconnection with evolution of other ideas. The present study, although sketchy and operating with overviews rather than with detailed pictures, has revealed interesting (in my opinion) aspects of man's attitude towards the Universe. To conclude the paper, I will collect some of them. I do not need to warn my reader that these conclusions are tentative ones; a more thorough study is required to obtain a more detailed and better founded picture.

1. It is a commonplace to speak about man's searching his place in the Universe. It seems that this saying is well founded in the history of science, philosophy, and literature. One could even say more strongly: man's looking for his place was often a driving force of scientific and philosophical inquiries. This is especially clearly visible in the Greek beginnings of philosophy and science.

2. However, sometimes also reciprocally, new scientific discoveries or successful theories gave a new momentum to philosophical (or theological) speculations on the role of man in the Universe. The extraterrestrial life debate is often a symptom of this process. A typical example is the post-Newtonian period in which the plurality of worlds dispute incomparably flourished.

${ }^{78}$ See, F. J. Tipler, The Omega Point Theory: A Model of an Evolving God, [in:] Physics, Philosophy and Theology-A Common Quest for Understanding, ed. R. J. Russell, W. R. Stoeger, G. V. Coyne, Vatican Observatory, Vatican City State 1988, pp. 313-331.

3. The popularity of the anthropic principles in our days can be (at least in part) explained by putting this phenomenon within the context of the above two conclusions. This corroborates the hypothesis, stated in the Introduction, that the present popularity of the anthropic principles is (at least in part) philosophically inspired.

4. The Copernican revolution is doubtlessly a turning point in the process of 
shaping man's relationship with the Universe. There are many misunderstandings and falsehoods, spread both in common views and comments to scientific texts, concerning historical and philosophical aspects of the Copernican revolution. One of the most popular ones is thinking about the role of the humanity in the preCopemican Universe in geometric terms (as occupying the geometric centre of the world), whereas the geometrization of space could be regarded only as a distant effect of the Copernicus work. However, the very fact that so many things are imputed to the Copernican revolution testifies about the prevailing influence it exercise upon our imagination.

5. In the pre-Copernican period people experienced the insignificance of man in the strongly theocentric Universe. However, strangely enough, the structure itself of the Universe was made out of almost purely anthropomorphic elements: language, imaginations, conceptual frame of reference, etc. were all of an anthropomorphic origin, an they totally permeated the Medieval Model of the Universe. In the post-Copemican period the situation is just opposite: while experimentation and the language of mathematics efficiently fight anthropomorphic approach to the world, the feeling of man's insignificance gradually gives place to believing in the absolute value of man as a „measure of all things”. One should notice that the border-line between the pre-Copernican period and the postCopemican period is Kepler's work rather than that of Copernicus himself, the last remaining a cause and a symbol. Moreover, for some authors, the pre-Copemican period lasts till long after Kepler's death.

6. The objectivation of the world, increasingly positivistic interpretations of science, and decline of religious thinking led to the feeling of a cosmic solitude, strangely coexisting with ,philosophies of human subjectivity" which stress the quasi-absolute role of man, mainly by ignoring achievements of the sciences and methods with the help of which they have been obtained.

7. The appearance of subjectivistic interpretations of quantum mechanics and anthropic principles makes an impresion of bridging the gap between the objective but dehumanized world and subjectivistic philosophies or ideologies. It is proclaimed by many as a long expected ,return of man to the sciences”.

8. Apart of all scientific merits of the anthropic principles (which in the case of the weak anthropic principle are unquestionable, although only provisory until true theoretical explanation is not obtainable), a doctrine they convey plays the role of an ideology in the Popper sense. This creates a danger to ,conflate science and ideology, and to muddle the distinction between scientific 
76 and ideological revolutions" $" 79$. The present literature devoted to various aspects of the anthropic principles testifies to the fact that this danger is a reality. In this situation the following Popper's words do not loose their actuality:

I think that it is quite a serious problem at a time when intellectuals, including scientists, are prone to fall for ideologies and intellectual fashions. This may well be due to the decline of religion, to the unsatisfied and unconscious needs of our fatherless society ${ }^{80}$.

${ }^{79}$ K. Popper, The Rationality, p. 87. so

Ibid. 